Supporting Information

\title{
Concentrations and the Photochemistry of Acetaldehyde, Glyoxal and Methylglyoxal in the Northwest Atlantic Ocean
}

\begin{abstract}
Yuting Zhu ${ }^{1}$ and David J. Kieber*
Department of Chemistry, State University of New York, College of Environmental Science and Forestry, 1 Forestry Drive, Syracuse, New York 13210

${ }^{1}$ Present Address: Wadsworth Center, New York State Department of Health, Albany, New York 12201, USA
\end{abstract}

*Corresponding Author: djkieber@esf.edu, Phone: 1-315-470-6951, Fax: 1-315-470-6856

Supporting Information is 21 pages including 5 figures and 2 tables 


\section{S1. Photon Exposure for Shipboard Solar Irradiation Experiments}

During the shipboard solar irradiation experiments, the nitrate and nitrite actinometers were placed alongside the quartz tubes to quantify the photon exposures received in the seawater bath from $311-335 \mathrm{~nm}$ and $330-380 \mathrm{~nm}$, respectively. ${ }^{1-3}$ Prior to an experiment, the actinometry solutions were pipetted into $5 \mathrm{~mL}$ borosilicate vials with no headspace and capped with green thermoset caps that contained Teflon-faced silicone inserts; the nitrite actinometry vials were wrapped with a Mylar-film filter, and both the nitrate and nitrite actinometry vials were enclosed in neutral-density screens. The preparation and analysis of the nitrate and nitrite actinometers are described elsewhere including a description of the photon exposure calculation. ${ }^{3}$ The response bandwidths (i.e., 311-335 $\mathrm{nm}$ and 330-380 nm) were calculated for the nitrate and nitrite actinometers following Jankowski et al. ${ }^{1,2}$

The solar irradiation was recorded every $15 \mathrm{~min}$ with the OL-754 spectroradiometer (Optronics, Inc.) from 290 to $600 \mathrm{~nm}$ with a $1 \mathrm{~nm}$ resolution. The OL-754 was placed on the 01 deck just behind the ship's bridge in an unshaded location. However, since the photochemical experiments were performed on the main deck near the ship's stern, far from the OL-754, absolute values of spectroradiometer data were not used. Instead, the chemical actinometers were used to quantify photon exposures because they were placed in the water bath alongside of the quartz tubes, and therefore more accurately quantified the light field experienced by the samples. Photon exposures from the two actinometers were converted to a UV photon exposure from 290 to $400 \mathrm{~nm}\left(E_{\text {incub }}\right.$, mol quanta $\left.\mathrm{m}^{-2}\right)$ using the following equation:

$$
E_{\text {incub }}=\frac{\left(E_{\text {nitrate }}+E_{\text {nitrite }}\right) \times \int_{290}^{400} E_{\lambda, \text { noon }} d \lambda}{\int_{311}^{335} E_{\lambda, \text { noon }} d \lambda+\int_{330}^{380} E_{\lambda, \text { noon }} d \lambda}
$$

where $E_{\text {nitrate }}$ and $E_{\text {nitrite }}$ are the photon exposure determined by the nitrate and nitrite actinometers (mol quanta $\mathrm{m}^{-2}$ ), respectively, and $E_{\lambda, \text { noon }}$ is the spectral solar irradiance (mol 
quanta $\mathrm{m}^{-2} \mathrm{~s}^{-1} \mathrm{~nm}^{-1}$ ) over the appropriate bandwidth (e.g., $311-335 \mathrm{~nm}$ ) recorded by the OL-754 spectroradiometer at solar noon during the day of the shipboard experiments.

\section{S2. Carbonyl Quantification}

After seawater samples were reacted with the DNPH reagent, they were injected into a Shimadzu Prominence high performance liquid chromatography (HPLC) system equipped with a SPD-20A/V UV-Vis absorbance detector set at 371 and $435 \mathrm{~nm}$. The HPLC column consisted of a Waters $8 \times 100 \mathrm{~mm}$ Nova-Pak cartridge with $4 \mu \mathrm{m} \mathrm{C}_{18}$ packing placed in a Waters $\mathrm{RCM}$ radial compression cartridge holder (Waters Associates, Milford, MA). The mobile phase consisted of solvent A (Milli Q water) and solvent B (ACN). All samples were injected into the HPLC using a $1.25 \mathrm{~mL}$ sample loop. A detailed description of the HPLC method used to quantify carbonyl concentrations in seawater is presented elsewhere. ${ }^{4}$ Carbonyl concentrations in the seawater samples and standards were corrected for the background concentration in the reagent blank. The reagent blank typically contained $\sim 1 \mathrm{nM}$ acetaldehyde and non-detectable levels of glyoxal and methylglyoxal. The limit of detection (LOD) of the method for a $1.25 \mathrm{~mL}$ injection and with a signal to noise ratio of two was $0.91,0.095$ and $0.078 \mathrm{nM}$, with corresponding coefficients of variation of $\sim 12,5$ and $9 \%$ for acetaldehyde, glyoxal and methylglyoxal, respectively.

\section{S3. Seawater Absorption Spectra}

The absorbance of $0.2 \mu \mathrm{m}$-filtered seawater was determined with a SD 2000 fiber optic spectrophotometer (Ocean Optics, Inc.) containing a $1.01 \mathrm{~m}$ pathlength flow cell pre-cleaned with Milli Q water and methanol; the flowcell pathlength was determined according to Cartisano et al. ${ }^{5}$ The cell was filled with seawater using a Rainin Rabbit-Plus peristaltic pump to gently 
pull the sample through the cell. Milli Q water or UV-irradiated $0.7 \mathrm{M} \mathrm{NaCl}$ solution ( $300 \mathrm{~W}$ Xenon lamp, $8 \mathrm{~h}$ ) was used as the reference. Baseline offsets were corrected by adjusting the absorbance $\left(A_{\lambda}\right)$ to zero between $630-640 \mathrm{~nm} .{ }^{6}$ The absorbance was converted to an absorbance coefficient $\left(a_{\lambda}, \mathrm{m}^{-1}\right)$ :

$$
a_{\lambda}=2.303 \frac{A_{\lambda}}{l}
$$

where $A_{\lambda}$ is the seawater absorbance at wavelength $\lambda(\mathrm{nm})$ and $l$ is the pathlength $(\mathrm{m})$.

\section{S4. ${ }^{14}$ C-Acetaldehyde Synthesis}

Ethanol is considerably more stable than acetaldehyde during storage, and through this synthesis we were able to prepare acetaldehyde as needed and avoid acetaldehyde decomposition during storage (e.g., via aldol condensation). ${ }^{14} \mathrm{C}$-labeled acetaldehyde was synthesized from uniformly ${ }^{14} \mathrm{C}$-labeled ethanol $(1 \mathrm{mCi} / \mathrm{mL}$, American Radiolabeled Chemicals, Inc.) using alcohol oxidase. ${ }^{7}$ The enzymatic stock solution was prepared by dissolving $3.3 \mathrm{mg}$ of $\sim 6 \mathrm{unit} / \mathrm{mg}$ alcohol oxidase (EC 1.1.3.13) from the yeast Hansenula sp. (Sigma-Aldrich) in $5 \mathrm{~mL}$ of $0.1 \mathrm{M}$ dibasic potassium phosphate $(>99.9 \%$, JT. Baker) solution $(\mathrm{pH}=8.9)$.

The synthesis was conducted by adding $100 \mu \mathrm{L}$ of the enzyme stock solution, $400 \mu \mathrm{L}$ of $0.1 \mathrm{M}$ potassium phosphate dibasic buffer and $100 \mu \mathrm{L}$ of $\sim 8 \mu \mathrm{M}{ }^{14} \mathrm{C}$ ethanol solution to $4.4 \mathrm{~mL}$ of Milli Q water in a $5 \mathrm{~mL}$ Qorpak vial. This solution was kept at $40{ }^{\circ} \mathrm{C}$ in a water bath for $4 \mathrm{~h}$. Once cooled, the reacted solution was centrifuged with a 30K Macrosep filter (PALL Scientific) to remove the enzyme. This synthesis was tested with nonradioactive ethanol; the average $( \pm \sigma)$ recovery was $103( \pm 7) \%(n=6) .{ }^{14} \mathrm{C}$ acetaldehyde was prepared no more than $72 \mathrm{~h}$ before the rooftop photolysis experiment and kept frozen before use. 


\section{S5. Carbonyl Photolysis Experiments}

The photochemical degradation of acetaldehyde was determined using ${ }^{14} \mathrm{C}$-labeled acetaldehyde freshly synthesized from uniformly labeled ${ }^{14} \mathrm{C}$ ethanol (see section $\mathrm{S} 4$ for ${ }^{14} \mathrm{C}$ acetaldehyde synthesis). The ${ }^{14} \mathrm{C}$ acetaldehyde-amended Milli $\mathrm{Q}$ water or $0.2-\mu \mathrm{m}$ filtered seawater (from SS1 and GB) contained $\sim 2 \mathrm{nM}{ }^{14} \mathrm{C}$ acetaldehyde. These samples were dispensed into quartz tubes that were placed in a water bath $\left(25 \pm 1^{\circ} \mathrm{C}\right)$. Triplicate light treatments, dark controls, and actinometry samples were exposed to sunlight for $\sim 8 \mathrm{~h}$ from $\sim 9: 30$ to 18:30 local time on the rooftop of the home laboratory in Syracuse, NY. Samples collected at four time points in each quartz tube were derivatized with the DNPH reagent for $\geq 4 \mathrm{~h}$ prior to HPLC analyses (see section S2 for HPLC details). The ${ }^{14} \mathrm{C}$-acetaldehyde concentration was quantified by counting the radioactivity of the acetaldehyde-2,4-dinitrophenylhydrazone peak collected from the HPLC effluent $(\sim 1.8 \mathrm{~mL}$ collected $)$. The radioactivity was counted using a Wallac model 1409 scintillation counter (Perkin-Elmer) after adding $4 \mathrm{~mL}$ of EcoLume ${ }^{\mathrm{TM}}$ (MP Biomedicals).

Glyoxal and methylglyoxal photolysis rates were not determined with ${ }^{14} \mathrm{C}$-labeled compounds, since they could not be synthesized easily prior to photochemical experiments. To determine glyoxal and methylglyoxal photolysis rates, rooftop solar-exposure experiments were conducted with Milli Q water or $0.2 \mu \mathrm{m}$-filtered seawater collected during the cruise and stored in $4 \mathrm{~L}$ Qorpak bottles in the dark at $4{ }^{\circ} \mathrm{C}$ until experiments were conducted in Syracuse, NY. Experiments were set up as previously described for the shipboard solar-exposure experiments using a circulating water bath, with drinking water from the faucet used to control the temperature at $\sim 23{ }^{\circ} \mathrm{C}$. For a given experiment, the temperature of the water bath varied by less than $2{ }^{\circ} \mathrm{C}$. For photolysis experiments, Milli Q water or seawater (collected from GB, SS1 or BI) 
were amended with $\sim 10-20 \mathrm{nM}$ glyoxal or methylglyoxal followed by dispensing these samples, and seawater or Milli Q water controls (with no amendments) into quartz tubes; parallel samples wrapped in aluminum foil served as dark controls. All dicarbonyl-amended treatments including the light and dark controls had three replicates. Dicarbonyl-amended treatments and dark controls, dark and light controls with no added glyoxal or methylglyoxal, and actinometers were placed in a water bath and exposed to sunlight for $\sim 8 \mathrm{~h}$ from $\sim 930$ to 1730 local time. Carbonylamended samples contained initial dicarbonyl concentrations that were $\sim 1$ order of magnitude higher than expected dicarbonyl concentrations photoproduced in unamended samples so that net photolysis would be observed in amended samples if photolysis was important (i.e., competitive with carbonyl photoproduction rates). At the end of each photolysis experiment, carbonyl concentrations and CDOM absorption spectra were determined in each quartz tube.

\section{S6. Air-Sea Flux}

Fluxes $\left(F_{\text {air-sea }}\right)$ of carbonyl compounds across the air-sea interface were computed using the Liss and Slater $^{8}$ two-layer model:

$$
F_{\text {air-sea }}=k_{T} \times\left(\frac{C_{a}}{H^{*}}-C_{w}\right)
$$

where $k_{T}$ is the gas transfer velocity $\left(\mathrm{cm} \mathrm{s}^{-1}\right), C_{a}$ and $C_{w}$ are the concentrations in the gas and aqueous phase, respectively $\left(\mathrm{mol} \mathrm{cm}{ }^{-3}\right)$, and $H^{*}$ is the apparent Henry's Law constant defined as the equilibrium ratio of the concentration in water to that in air. For acetaldehyde and glyoxal, $H^{*}$ values were adjusted for differences in the sea-surface temperature. ${ }^{9,10} k_{T}$ was calculated based on the following equation:

$$
\frac{1}{k_{T}}=\frac{1}{\alpha \times k_{w}}+\frac{1}{H^{*} \times k_{a}}
$$


where the total transfer resistance $\left(\frac{1}{k_{T}}\right)$ is the sum of those in the air and aqueous phases. $k_{a}$ was derived following Duce et al. ${ }^{11}$ For acetaldehyde, we followed Beale et al. ${ }^{12,13}$ to calculate $k_{w}$. The chemical enhancement factor, $\alpha$, accounts for the increased transfer due to hydration. $\alpha$ was set to 2 for acetaldehyde following Zhou and Mopper. ${ }^{14}$ For glyoxal and methylglyoxal, which are highly soluble in water, $k_{w}$ was not computed because $k_{T} \approx H^{*} k_{a}$.

\section{S7. Depth-Dependent Photoproduction Rates}

Photoproduction data from the shipboard solar irradiation experiments were extrapolated to depth-dependent surface mixed layer photoproduction rates at the four main hydrographic stations. To determine depth-dependent rates, it was first necessary to calculate the cloud correction factor $\left(C F_{U V}\right)$ for UV radiation $(290-400 \mathrm{~nm})$ using the level-3 monthly-averaged OMUVBd product from the OMI dataset at the four main hydrographic stations for September and October 2016. OMUVBd product was downloaded from NASA's Goddard Earth Sciences Data and Information Services Center (GES DISC, https://disc.gsfc.nasa.gov/). The $C F_{U V}$ is defined as:

$$
C F_{U V}=\frac{E_{C L, \lambda, U V}}{E_{\lambda, U V, \text { clear }}}
$$

where $E_{\lambda, U V}$ is the cloud-corrected spectral UV irradiance and $E_{\lambda, U V, \text { clear }}$ is the clear-sky spectral UV irradiance at the earth's surface $\left(\mathrm{W} \mathrm{m}^{-2} \mathrm{~nm}^{-1}\right) . C F_{U V}$ was calculated at four different wavelength, 308, 310, 324 and $380 \mathrm{~nm}$, based on the corresponding ratio of the cloud-corrected to clear-sky solar noontime UV irradiance at each respective wavelength. For this work, we assumed a constant $C F_{U V}$ value from 290 to $400 \mathrm{~nm}$ after averaging $C F_{U V}$ values calculated for these four wavelengths. Details for the OMI UV products are provided by Tanskanen et al. ${ }^{15}$ Daily variations in cloudiness were also not considered, which introduced maximum 
uncertainties of $25-35 \% .{ }^{16}$ With these simplifications, the cloud-corrected 24-h average spectral UV irradiance above the water surface $\left(E_{C L, \lambda, 0^{+}}\right.$, mol quanta $\left.\mathrm{m}^{-2} \mathrm{~d}^{-1} \mathrm{~nm}^{-1}\right)$ was quantified by multiplying $E_{\lambda, 0^{+}}$(See section S8 for details) by the constant $C F_{U V}$ value from 290 to $400 \mathrm{~nm}$.

The loss of radiation at the air-seawater interface was calculated following the procedure outlined in Galí et al. ${ }^{17}$ The final product is the cloud-corrected 24-h average, spectral scalar irradiance immediately below the air-seawater interface $\left(E_{C L, \lambda, 0^{-}}\right.$, mol quanta $\left.\mathrm{m}^{-2} \mathrm{~d}^{-1} \mathrm{~nm}^{-1}\right)$ :

$$
E_{C L, \lambda, 0^{-}}=E_{C L, \lambda, 0^{+}} \times\left(f_{\text {diff }, \lambda} \times(1-0.066)+f_{\text {dir }, \lambda} \times\left(1-\rho_{\text {Fresnel }}\right)\right)
$$

where $f_{d i f f, \lambda}$ and $f_{d i r, \lambda}$ are the wavelength-dependent fractions of the diffuse beam and the direct beam in the global irradiance modeled by SMARTS, respectively. We used an assumed constant reflection of $6.6 \%$ for the diffuse irradiance. ${ }^{17} \rho_{\text {Fresnel }}$ corrects the reflected direct beam and was calculated according to the Fresnel's equation: ${ }^{18}$

$$
\rho_{\text {Fresnel }}=\frac{1}{2} \times\left\{\left[\frac{\sin \left(\theta_{i}-\theta_{t}\right)}{\sin \left(\theta_{i}+\theta_{t}\right)}\right]^{2}+\left[\frac{\tan \left(\theta_{i}-\theta_{t}\right)}{\tan \left(\theta_{i}+\theta_{t}\right)}\right]^{2}\right\}
$$

where $\theta_{i}$ is the incident solar zenith angle and $\theta_{t}$ is the transmitted angle. The solar zenith angle was determined by the SMARTS model. $\theta_{t}$ was obtained from Snell's Law, using refractive index values of 1.0 and 1.34 for air and seawater, respectively.

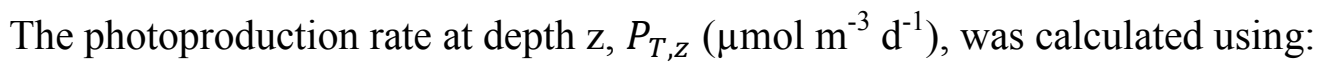

$$
P_{T, Z}=\Delta C_{T} \times \frac{\int_{290}^{400} E_{C L, \lambda, 0}-d \lambda}{E_{\text {incub }}} \times e^{-K_{d, U V} \times z}
$$

where $\Delta C_{T}$ is the difference in the carbonyl concentration $\left(\mathrm{mol} \mathrm{m}^{-3}\right)$ between the irradiated seawater samples and dark controls obtained from the shipboard solar irradiation experiments at temperature $T, K_{d, U V}\left(\mathrm{~m}^{-1}\right)$ is the average diffuse attenuation coefficient for downwelling irradiance from 290 to $400 \mathrm{~nm}$, and $\mathrm{z}$ is the depth (m). Diffuse attenuation coefficients for downwelling irradiance $\left(K_{d}\right)$ at $320,340,380,412,443$ and $490 \mathrm{~nm}$ were retrieved for 
September-October 2016 using the Sea $U V$ algorithm with updated parameters ${ }^{19,20}$ from MODIS Aqua reflectance $\left(R_{r s}\right)$. Wavelength-dependent $K_{d}$ values from 290 to $400 \mathrm{~nm}\left(K_{d, U V, \lambda}\right)$ were determined by fitting the Sea $U V$ retrieved data at the six wavelengths to a simple exponential decay function. ${ }^{21} K_{d, U V}$ was calculated by averaging $K_{d, U V, \lambda}$ from 290 to $400 \mathrm{~nm} . R_{r s}$ data at the four main hydrographic stations from September to October 2016 were downloaded from GES DISC.

For methylglyoxal, $P_{T, Z}$ was corrected by adding a loss term (S9) to equation $\mathrm{S} 8$ to account for its photochemical degradation:

$$
P_{l o s s, z}=k_{P-o b s} \times \int_{290}^{400} E_{C L, \lambda, 0^{-}} d \lambda \times[M G] \times e^{-K_{d, U V} \times z}
$$

where $P_{\text {loss }, z}$ is the loss rate of methylglyoxal at depth $\mathrm{z}\left(\mu \mathrm{mol} \mathrm{m} \mathrm{m}^{-3}\right)$, $[\mathrm{MG}]$ is the methylglyoxal concentration in the surface mixed layer $\left(\mathrm{mol} \mathrm{m}^{-3}\right), k_{P-o b s}$ is the pseudo-first order photolysis rate constant $\left(\left(\mathrm{mol} \text { quanta } \mathrm{m}^{-2}\right)^{-1}\right)$ calculated using equation 1 in the main text. Note that the value of $k_{P-o b s}$ for station SS1 (main text, Table 2) was also used for station SS2.

\section{S8. Climatological Spectral Scalar Irradiance}

The 24-h average daily spectral scalar irradiance immediately above the water surface

$\left(E_{\lambda, 0^{+}}\right.$, mol quanta $\left.\mathrm{m}^{-2} \mathrm{~d}^{-1} \mathrm{~nm}^{-1}\right)$ from 280 to $4000 \mathrm{~nm}$ was determined on days the ship occupied the four main hydrographic stations using the Simple Model of the Atmospheric Radiative Transfer of Sunshine (SMARTS) model version 2.9.5. ${ }^{22}$ Monthly averaged data of total column ozone concentrations from the Aura Ozone Monitoring Instrument (OMI) and daily aerosol optical depth at $550 \mathrm{~nm}\left(\mathrm{AOD}_{550 \mathrm{~nm}}\right)$ from the Moderate-Resolution Imaging Spectroradiometer (MODIS) at the four main hydrographic stations were used as SMARTS inputs. Ozone and $\mathrm{AOD}_{550 \mathrm{~nm}}$ data were obtained from GES DISC. In the SMARTS model, the pressure 
immediately above the water surface was calculated based on the latitude; water vapor and trace gas absorption were calculated using the appropriate reference atmosphere selected based on latitude and season (e.g., mid-latitude summer); the Shettle and Fenn ${ }^{23}$ maritime aerosol model was used in SMARTS to determine the AOD as a function of wavelength using satellite-retrieved AOD550; and the seawater spectral albedo data file was selected.

\section{S9. Diatom Sources of Acetaldehyde}

The only data available to show that marine algae are a source of carbonyl compounds in seawater is from the culture work of Halsey et al. ${ }^{24}$ They grew an axenic culture of the diatom, Thalassiosira pseudonana, to the exponential phase at a relatively low PAR (photosynthetically active radiation, $400-700 \mathrm{~nm}$ ) irradiance of $\sim 50 \mu \mathrm{mol}$ photons $\mathrm{m}^{-2} \mathrm{~s}^{-1}$, and then transferred the cultures to a bubbling chamber wherein they were bubbled and exposed to irradiance levels of 50 , 100,150 or $1500 \mu \mathrm{mol}$ photons $\mathrm{m}^{-2} \mathrm{~s}^{-1}$. In all treatments, acetaldehyde was released into the dissolved phase, and production increased exponentially with short-term exposure to an increasing PAR intensity. They used the following equation initially introduced by Gantt et al. ${ }^{25}$ to fit acetaldehyde production rates by $T$. pseudonana in seawater:

$$
P_{\text {bio }}=E F \times \ln \left(P A R_{z}\right)^{2}
$$

where $P_{b i o}$ is the acetaldehyde production rate $\left(\mu \mathrm{mol}(\mathrm{g} \mathrm{Chl} a)^{-1} \mathrm{~h}^{-1}\right), E F$ is the biological emission factor $\left(E F=3.6 \pm 0.3 \mu \mathrm{mol}(\mathrm{g} \mathrm{Chl} a)^{-1} \mathrm{~h}^{-1}\right)$ for acetaldehyde from the particulate to dissolved phase, and $P A R_{z}$ is the wavelength-integrated photosynthetically active radiation in seawater at depth $\mathrm{z}(\mathrm{m})$ at the oceanographic station where equation S10 is applied ( $\mu$ mol quanta $\left.\mathrm{m}^{-2} \mathrm{~s}^{-1}\right)$. 
To obtain $P A R_{z}$ in equation $\mathrm{S} 10$, we first calculated the cloud-corrected spectral scalar irradiance above the water surface in the visible range between 400 and $700 \mathrm{~nm}\left(P A R_{C L, \lambda, 0^{+}}\right.$, mol quanta $\left.\mathrm{m}^{-2} \mathrm{~d}^{-1} \mathrm{~nm}^{-1}\right)$ :

$$
P A R_{C L, \lambda, 0^{+}}=\frac{E_{\text {Shortwave }}}{\int_{295}^{2800} E_{\lambda, 0^{+}} d \lambda} E_{\lambda, 0^{+}}
$$

where $E_{\text {shortwave }}$ is the average daily shortwave solar irradiance in air from 295 to $2800 \mathrm{~nm}$ (mol quanta $\mathrm{m}^{-2} \mathrm{~d}^{-1}$ ) measured with an Eppley Precision Pyranometer installed on the R/V Endeavor. The ratio between the measured and modeled irradiance (see section S8 for the calculation of $\left.E_{\lambda, 0^{+}}\right)$integrated between 295 and $2800 \mathrm{~nm}$ was used as a cloud-correction factor to convert $E_{\lambda, 0^{+}}$to $P A R_{C L, \lambda, 0^{+}}$between 400 and $700 \mathrm{~nm}$. We then corrected for the loss of $P A R_{C L, \lambda, 0^{+}}$at the air-sea interface similar to what we introduced in section $\mathrm{S} 7$ for the correction of $\mathrm{UV}$ at the air-sea interface; we assumed $6.6 \%$ reflection for the $P A R_{C L, \lambda, 0^{+}}$diffuse beam irradiance, and the $P A R_{C L, \lambda, 0^{+}}$reflected direct beam irradiance was estimated using the Fresnel's equation (equation S7). The final product was the cloud-corrected, spectral irradiance just below the water surface in the visible range from 400 to $700 \mathrm{~nm}\left(P A R_{C L, \lambda, 0^{-}}\right.$, mol quanta $\left.\mathrm{m}^{-2} \mathrm{~d}^{-1} \mathrm{~nm}^{-1}\right)$. Photosynthetically active radiation in seawater at depth $\mathrm{z}, P A R_{z}$, was calculated as:

$$
P A R_{z}=\int_{400}^{700} P A R_{C L, \lambda, 0^{-}} d \lambda \times e^{-K_{d, V i s} \times z}
$$

See section S7 for the retrieval of $K_{d}$ at six wavelengths from MODIS $R_{r s}$. Likewise, $K_{d, V i s}$ was determined by averaging the fitted $K_{d}$ spectrum (determined by fitting the Sea $U V$ retrieved data at the six wavelengths to a simple exponential decay function) from 400 to $700 \mathrm{~nm} . P A R_{z}$ was converted from mol quanta $\mathrm{m}^{-2} \mathrm{~d}^{-1}$ to $\mu$ mol quanta $\mathrm{m}^{-2} \mathrm{~s}^{-1}$ assuming eight hours of solar irradiation. The Chl $a$ concentration was measured in seawater samples from the seawater surface $(0-5 \mathrm{~m})$, and we assumed that the Chl $a$ concentration was constant in the surface 
mixed layer. The fraction of diatoms relative to the total $\mathrm{Chl} a\left(\mu \mathrm{g} \mathrm{L}{ }^{-1}\right)$ concentration was estimated according to Hirata et al. ${ }^{26}$ :

$$
f_{\text {Diatom }}=\left[a_{0}+e^{a_{1} \times x+a_{2}}\right]^{-1}
$$

where $f_{\text {Diatom }}$ represents the fraction of the $\mathrm{Chl} a$ concentration contributed by diatoms and $x=\log _{10}(\mathrm{Chl} a)$; values of the fitting parameters $a_{0}, a_{1}$, and $a_{2}$ are 1.3272, -3.9828 , and 0.1953, respectively. ${ }^{26}$

Equation S10 is used here as a very crude, preliminary estimate to extrapolate labdetermined acetaldehyde production rates measured by Halsey et al. ${ }^{24}$ to diatom production rates, $P_{\text {diatom }}$, in the surface mixed layer at the four main hydrographic stations shown in Figure S1. This estimate is limited by uncertainties associated with extrapolating lab culture results to the field, and by uncertainties associated with bubbling cultures to quantify acetaldehyde as this may have induced its release into the dissolved phase. ${ }^{27,28}$ Likewise, extrapolating results from one diatom to all diatoms, to all times of day, to all growth phases, and without consideration of cell lysis due to grazing or viral infection, is highly uncertain, especially with respect to EF. Given these caveats, the algal production rate of acetaldehyde can be estimated from Chl $a$ using equation S10, with the understanding that extrapolating culture data to an oceanic setting is highly uncertain. 


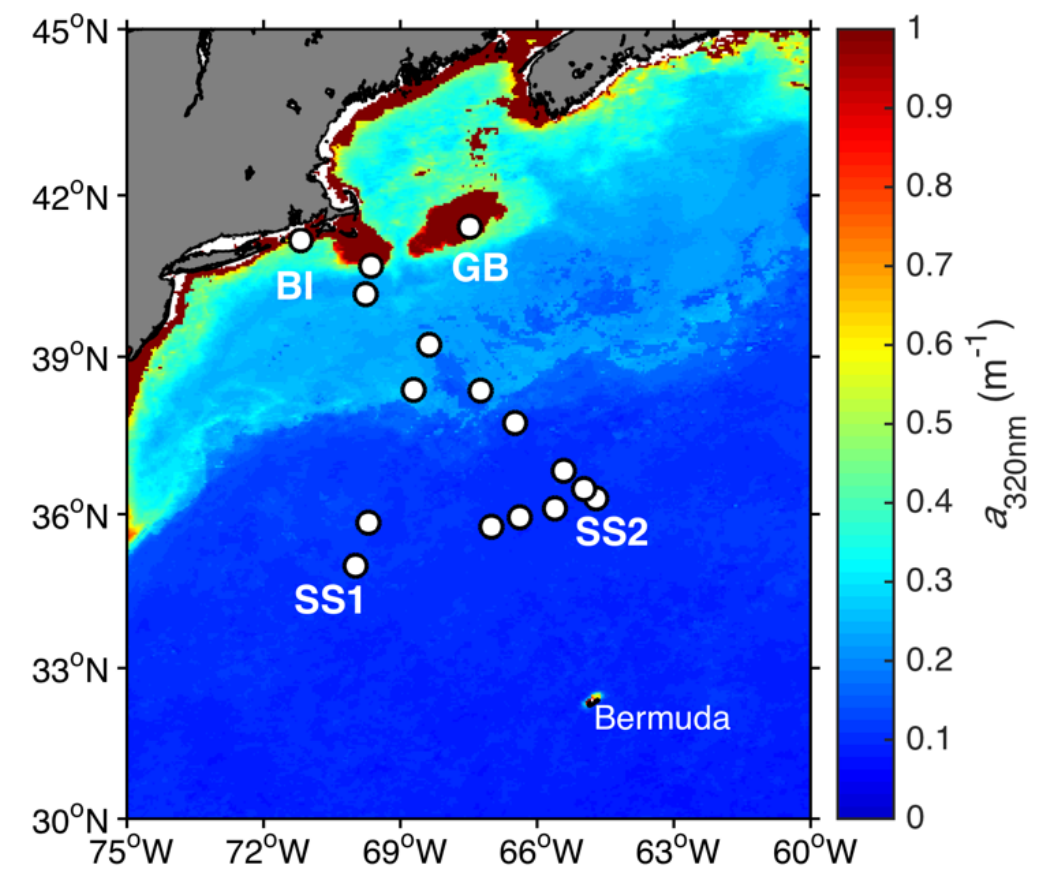

Figure S1 Locations of sampling stations superimposed on the satellite-derived CDOM absorption coefficient at $320 \mathrm{~nm}\left(a_{320 \mathrm{~nm}}, \mathrm{~m}^{-1}\right)$ in September-October 2016 using the SeaCDOM algorithm ${ }^{29}$ and reflectance data obtained from the Moderate-Resolution Imaging Spectroradiometer (MODISAqua, https://oceancolor.gsfc.nasa.gov/). The main hydrographic sampling locations are noted in the map as GB = Georges Bank, SS1 = Sargasso Sea 1, SS2 = Sargasso Sea 2, and BI = coastal Rhode Island near Block Island. The other sampling stations correspond to samples collected during the transect between stations. The map was generated with MATLAB 2018a employing the m_map toolbox (https://www.eoas.ubc.ca/ rich/map.html); Data for generating the coastline was obtained from a Global Self-consistent, Hierarchical, High-resolution Geography Database (GSHHG, https://www.soest.hawaii.edu/pwessel/gshhg/). 


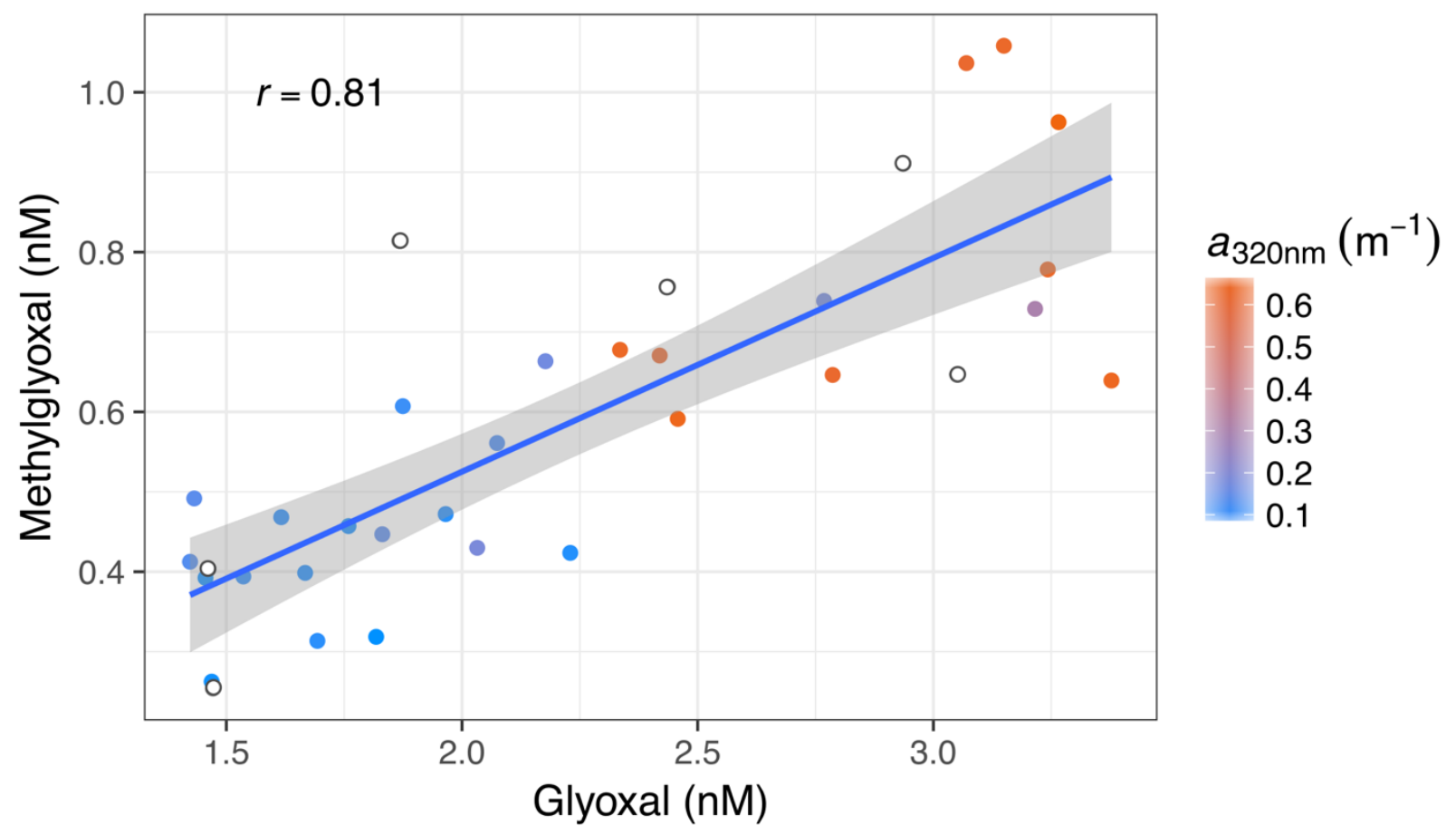

Figure S2 Surface mixed layer seawater concentrations of methylglyoxal measured in the Northwest Atlantic Ocean plotted against glyoxal concentrations measured in the same water samples. The solid line represents the best-fit line by simple linear regression. The best-fit line has a positive slope of $0.267(p<0.001)$ with a y-intercept that is not significantly different from zero $(p=0.9)$. The grey area is the $95 \%$ confidence interval. Color-filled circles represent samples with corresponding CDOM absorbance coefficients at $320 \mathrm{~nm}\left(a_{320 \mathrm{~nm}}\right)$, and open white circles depict samples for which $a_{320 \mathrm{~nm}}$ data are not available. 

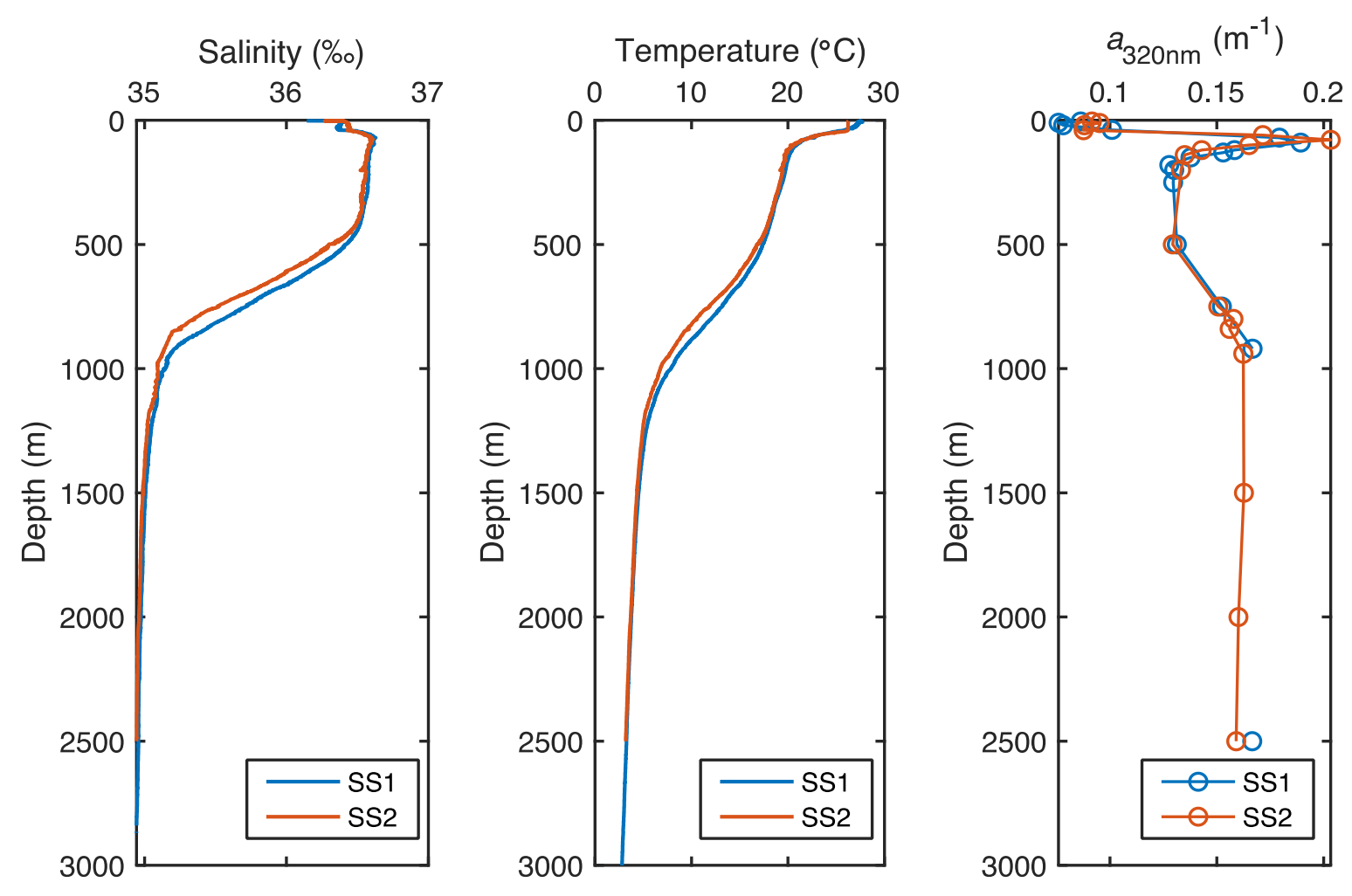

Figure S3 Depth profiles of salinity, temperature, and the absorbance coefficient at $320 \mathrm{~nm}$ $\left(a_{320 \mathrm{~nm}}\right)$ at stations SS1 and SS2. See Figure 2 in the main text for depth profiles of carbonyl concentrations determined from the same CTD casts. 

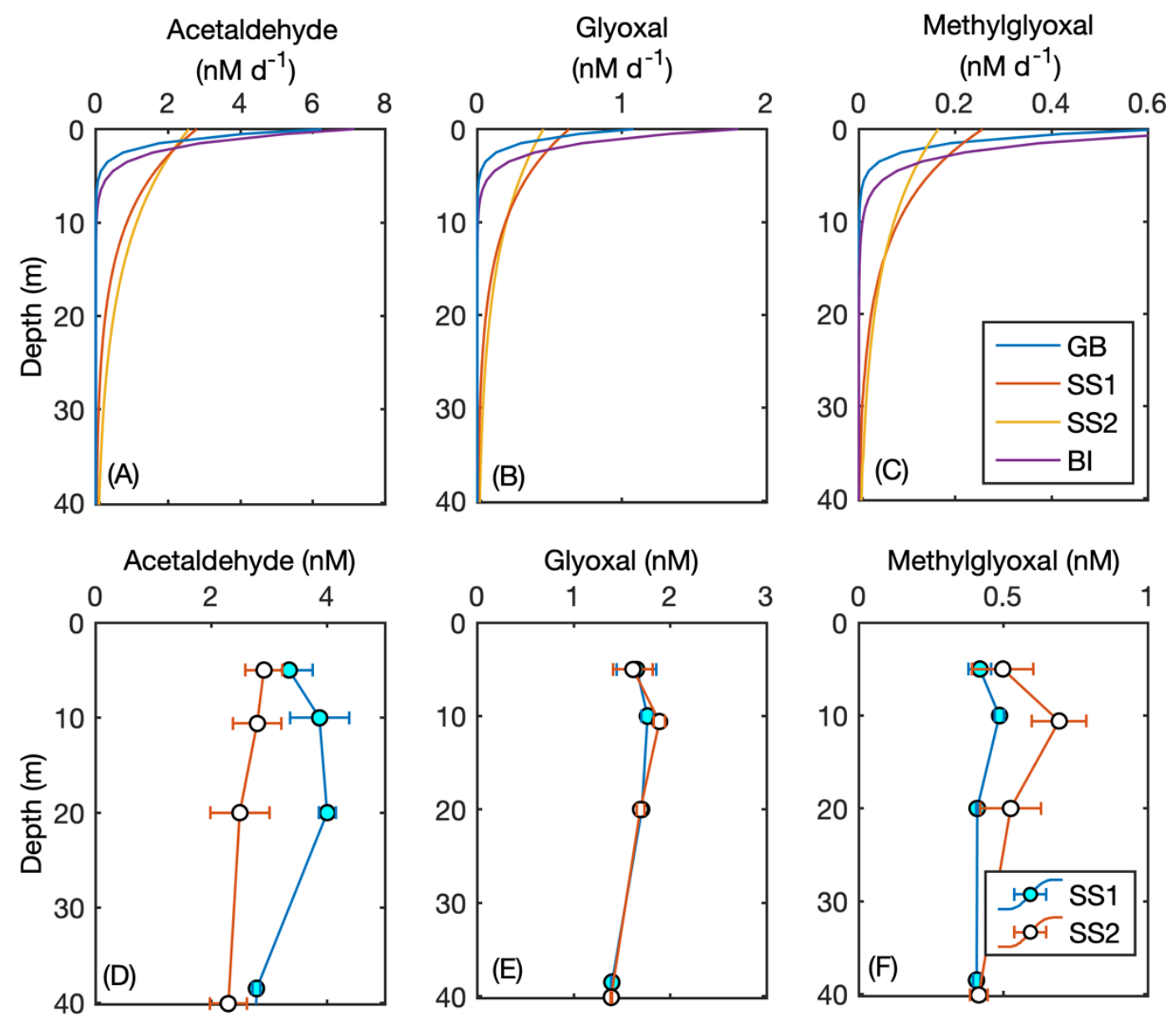

Figure S4 Modeled depth-dependent photoproduction rates determined for (A) acetaldehyde, (B) glyoxal and (C) methylglyoxal at the four main hydrographic stations: Georges Bank (GB), coastal Rhode Island near Block Island (BI), Sargasso Sea station 1 (SS1), and Sargasso Sea station 2 (SS2). Depth profiles of (D) acetaldehyde, (E) glyoxal and (F) methylglyoxal concentrations that were measured during the EN589 research cruise aboard the R/V Endeavor are shown in the top $40 \mathrm{~m}$ for direct comparison to modeled photoproduction rates. Error bars denote the standard deviation $(n=3)$; for several samples the error bar is smaller than the diameter of the symbol. 

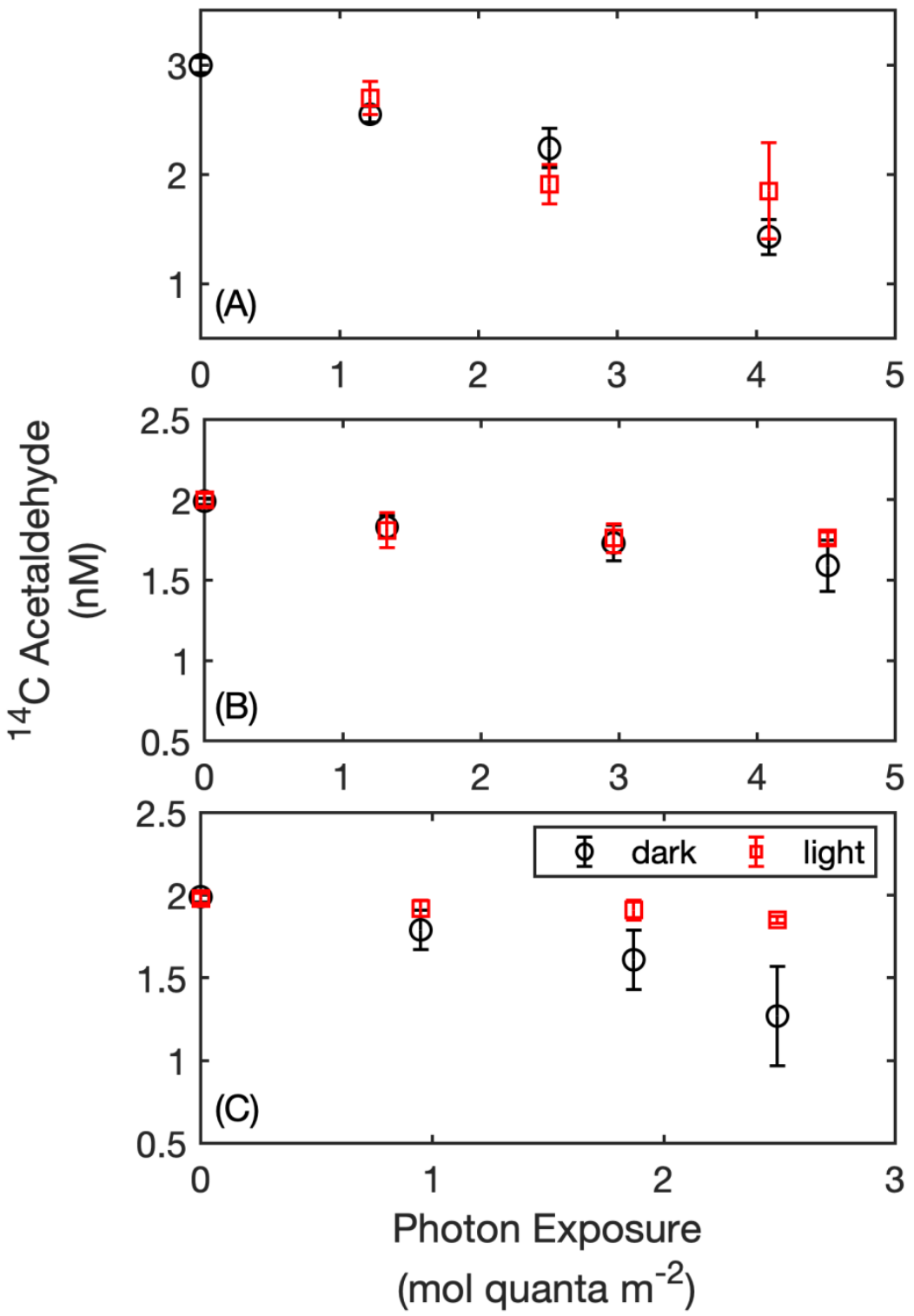

Figure S5 Concentration of ${ }^{14} \mathrm{C}$ acetaldehyde in (A) Milli Q water and 0.2- $\mu \mathrm{m}$ filtered seawater collected from stations (B) SS1 and (C) GB when incubated in the dark or exposed to sunlight in a water bath located on the roof of Jahn Laboratory in Syracuse, NY. The photon exposure between 290 and $400 \mathrm{~nm}$ was determined from the photon exposure quantified by nitrate and 
nitrite actinometry (see section S1). Error bars denote the standard deviation $(n=3)$; for several samples the error bar is smaller than the symbol.

Table S1 Geographic locations and seawater chemical properties for seawater collected from near-surface seawater in the Northwest Atlantic Ocean. The letter U denotes underway samples.

\begin{tabular}{cccccc}
\hline Station & $\begin{array}{c}\text { Latitude } \\
\left({ }^{\circ} \mathrm{N}\right)\end{array}$ & $\begin{array}{c}\text { Longitude } \\
\left({ }^{\circ} \mathrm{W}\right)\end{array}$ & $\begin{array}{c}\text { Salinity } \\
(\mathrm{ppt})\end{array}$ & $\begin{array}{c}\text { Temperature } \\
\left({ }^{\mathrm{a}} \mathrm{C}\right)\end{array}$ & $\begin{array}{c}\text { Chl }^{\mathrm{a}} \\
\left(\mu \mathrm{g} \mathrm{L}^{-1}\right)\end{array}$ \\
\hline U1 & 40.69 & 69.64 & 34.00 & 17.3 & 0.47 \\
GB & 41.40 & 67.47 & 32.53 & 18.6 & 2.99 \\
U2 & 39.22 & 68.37 & 35.55 & 25.2 & 0.08 \\
U3 & 38.37 & 68.71 & 34.33 & 25.1 & 0.02 \\
U4 & 35.83 & 69.70 & 36.41 & 27.2 & 0.04 \\
SS1 & 35.04 & 69.98 & 36.42 & 27.0 & 0.03 \\
U5 & 35.76 & 67.00 & 35.54 & 28.6 & 0.06 \\
U6 & 35.94 & 66.38 & 35.55 & 29.0 & 0.05 \\
U7 & 36.11 & 65.61 & 35.62 & 28.9 & 0.04 \\
SS2 & 36.26 & 64.78 & 36.20 & 26.4 & 0.05 \\
U8 & 36.48 & 64.97 & 35.69 & 26.3 & 0.04 \\
U9 & 36.83 & 65.41 & 35.60 & 27.0 & 0.08 \\
U10 & 37.75 & 66.49 & 35.64 & 26.2 & 0.04 \\
U11 & 38.36 & 67.24 & 34.81 & 24.1 & 0.08 \\
U12 & 40.17 & 69.77 & 35.07 & 23.0 & 0.15 \\
BI & 41.18 & 71.16 & 32.16 & 17.3 & 2.27 \\
\hline Data & & & & \\
\hline
\end{tabular}

${ }^{\mathrm{a}}$ Data reported here denote average values. 
Table S2 Calculated, average depth-integrated photochemical production and loss fluxes of acetaldehyde (C2), glyoxal $(\mathrm{G})$ and methylglyoxal $(\mathrm{MG})$ in the surface mixed layer at the four hydrographic stations.

\begin{tabular}{|c|c|c|c|c|}
\hline \multirow[t]{2}{*}{$\overline{\text { Station }}$} & \multicolumn{3}{|c|}{$\begin{array}{l}\text { Photochemical Production } \\
\qquad\left(\mu \mathrm{mol} \mathrm{m} \mathrm{d}^{-2} \mathrm{~d}^{-1}\right)\end{array}$} & \multirow{2}{*}{$\begin{array}{c}\begin{array}{c}\text { Photochemical Loss } \\
\left(\mu \mathrm{mol} \mathrm{m} \mathrm{m}^{-2} \mathrm{~d}^{-1}\right)\end{array} \\
\mathrm{MG}\end{array}$} \\
\hline & $\mathrm{C} 2$ & $\mathrm{G}$ & $\mathrm{MG}^{\mathrm{a}}$ & \\
\hline GB & 7.1 & 1.2 & 0.72 & 0.12 \\
\hline SS1 & 28.7 & 6.5 & 2.6 & 0.19 \\
\hline $\mathrm{SS} 2$ & 36.1 & 6.4 & 2.3 & 0.18 \\
\hline BI & 11.3 & 2.9 & 1.4 & 0.34 \\
\hline
\end{tabular}

${ }^{a}$ Photoproduction fluxes of methylglyoxal extrapolated from shipboard incubation experiments were corrected by adding a photochemical loss term, which was estimated using the pseudo-first order photolysis rate constant $\left(k_{p-o b s}\right)$ determined from the rooftop photolysis experiments. Details of this calculation are presented in section S7 in the supporting information. 


\section{S10. References}

(1) Jankowski, J. J.; Kieber, D. J.; Mopper, K. Nitrate and nitrite ultraviolet actinometers. Photochem. Photobiol. 1999, 70 (3), 319-328.

(2) Jankowski, J. J.; Kieber, D. J.; Mopper, K.; Neale, P. J. Development and intercalibration of ultraviolet solar actinometers. Photochem. Photobiol. 2000, 71 (4), 431-440.

(3) Kieber, D. J.; Toole, D. A.; Jankowski, J. J.; Kiene, R. P.; Westby, G. R.; del Valle, D. A.; Slezak, D. Chemical "light meters" for photochemical and photobiological studies. Aquat. Sci. 2007, 69 (3), 360-376.

(4) Zhu, Y.; Kieber, D. J. Wavelength and temperature-dependent apparent quantum yields for photochemical production of carbonyl compounds in the North Pacific Ocean. Environ. Sci. Technol. 2018, 52 (4), 1929-1939.

(5) Cartisano, C. M.; Del Vecchio, R.; Blough, N. V. A calibration/validation protocol for long/multi-pathlength capillary waveguide spectrometers. Limnol. Oceanogr. Methods 2018, 16 (11), 773-786.

(6) Kieber, D. J.; Toole, D. A.; Kiene, R. P. Chromophoric Dissolved Organic Matter Cycling during a Ross Sea Phaeocystis antarctica Bloom. In Smithsonian at the Poles: Contributions to International Polar Year Science; Krupnik, I., Lang, M. A., Miller, S. E., Eds.; Smithsonian Institution Scholarly Press, 2009; pp 319-333.

(7) Kieber, R. J.; Guy, A. L.; Roebuck, J. A.; Carroll, A. L.; Mead, R. N.; Jones, S. B.; Giubbina, F. F.; Campos, M. L. A. M.; Willey, J. D.; Avery, G. B. Determination of ambient ethanol concentrations in aqueous environmental matrixes by two independent analyses. Anal. Chem. 2013, 85 (12), 6095-6099.

(8) Liss, P. S.; Slater, P. G. Flux of gases across the air-sea interface. Nature 1974, 247 (5438), 181-184.

(9) Zhou, X.; Mopper, K. Apparent partition coefficients of 15 carbonyl compounds between air and seawater and between air and freshwater; implications for air-sea exchange. Environ. Sci. Technol. 1990, 24 (12), 1864-1869.

(10) Ip, H. S. S.; Huang, X. H.H.; Yu, J.Z. Effective Henry's law constants of glyoxal, glyoxylic acid, and glycolic acid. Geophys. Res. Lett. 2009, 36 (1), L01802.

(11) Duce, R. A.; Liss, P. S.; Merrill, J. T.; Atlas, E. L.; Buat-Menard, P.; Hicks, B. B.; Miller, J. M.; Prospero, J. M.; Arimoto, R.; Church, T. M.; Ellis, W.; Galloway, J. N.; Hansen, L.; Jickells, T. D.; Knap, A. H.; Reinhardt, K. H.; Schneider, B.; Soudine, A.; Tokos, J. J.; Tsunogai, S.; Wollast, R.; Zhou, M. The atmospheric input of trace species to the world ocean. Global Biogeochem. Cycles 1991, 5 (3), 193-259.

(12) Beale, R.; Dixon, J. L.; Arnold, S. R.; Liss, P. S.; Nightingale, P. D. Methanol, acetaldehyde, and acetone in the surface waters of the Atlantic Ocean. J. Geophys. Res. C 2013, 118 (C10), 5412-5425.

(13) Beale, R. Quantification of Oxygenated Volatile Organic Compounds in Seawater. Doctoral Dissertation, University of East Anglia, 2011.

(14) Zhou, X.; Mopper, K. Photochemical production of low-molecular-weight carbonyl compounds in seawater and surface microlayer and their air-sea exchange. Mar. Chem. 1997, 56 (3-4), 201-213.

(15) Tanskanen, A.; Krotkov, N. A.; Herman, J. R.; Arola, A. Surface ultraviolet irradiance from OMI. IEEE Trans. Geosci. Remote Sens. 2006, 44 (5), 1267-1271.

(16) Bugliaro, L.; Mayer, B.; Meerkötter, R.; Verdebout, J. Potential and limitations of space- 
based methods for the retrieval of surface UV-B daily doses: A numerical study. $J$. Geophys. Res. D 2006, 111 (D23), D23207.

(17) Galí, M.; Kieber, D. J.; Romera-Castillo, C.; Kinsey, J. D.; Devred, E.; Pérez, G. L.; Westby, G. R.; Marrasé, C.; Babin, M.; Levasseur, M.; Duarte, C. M.; Agustí, S.; Simó, R. CDOM sources and photobleaching control quantum yields for oceanic DMS photolysis. Environ. Sci. Technol. 2016, 50 (24), 13361-13370.

(18) Hecht, E. Optics, 5th ed.; Pearson Education: London, 2016.

(19) Fichot, C. G.; Sathyendranath, S.; Miller, W. L. SeaUV and SeaUVC: Algorithms for the retrieval of UV/Visible diffuse attenuation coefficients from ocean color. Remote Sens. Environ. 2008, 112 (4), 1584-1602.

(20) Cao, F.; Fichot, C. G.; Hooker, S. B.; Miller, W. L. Improved algorithms for accurate retrieval of UV/visible diffuse attenuation coefficients in optically complex, inshore waters. Remote Sens. Environ. 2014, 144, 11-27.

(21) Fichot, C. G.; Miller, W. L. An approach to quantify depth-resolved marine photochemical fluxes using remote sensing: Application to carbon monoxide $(\mathrm{CO})$ photoproduction. Remote Sens. Environ. 2010, 114 (7), 1363-1377.

(22) Gueymard, C. A. Parameterized transmittance model for direct beam and circumsolar spectral irradiance. Sol. Energy 2001, 71 (5), 325-346.

(23) Shettle, E. P.; Fenn, R. W. Models for the Aerosols of the Lower Atmosphere and the Effects of Humidity Variations on Their Optical Properties (No. AFGL-TR-79-0214). Air Force Geophysics Lab, Hanscom Afb, MA. 1979.

(24) Halsey, K. H.; Giovannoni, S. J.; Graus, M.; Zhao, Y.; Landry, Z.; Thrash, J. C.; Vergin, K. L.; de Gouw, J. Biological cycling of volatile organic carbon by phytoplankton and bacterioplankton. Limnol. Oceanogr. 2017, 62 (6), 2650-2661.

(25) Gantt, B.; Meskhidze, N.; Kamykowski, D. A new physically-based quantification of marine isoprene and primary organic aerosol emissions. Atmos. Chem. Phys. 2009, 9, 4915-4927.

(26) Hirata, T.; Hardman-Mountford, N. J.; Brewin, R. J. W.; Aiken, J.; Barlow, R.; Suzuki, K.; Isada, T.; Howell, E.; Hashioka, T.; Noguchi-Aita, M.; Yamanaka, Y. Synoptic relationships between surface Chlorophyll-a and diagnostic pigments specific to phytoplankton functional types. Biogeosciences 2011, 8, 311-327.

(27) Wolfe, G. V.; Strom, S. L.; Holmes, J. L.; Radzio, T.; Brady Olson, M. Dimethylsulfoniopropionate cleavage by marine phytoplankton in response to mechanical, chemical, or dark stress. J. Phycol. 2002, 38 (5), 948-960.

(28) Chalmers, J. J. Cells and bubbles in sparged bioreactors. Cytotechnology 1994, 15 (1-3), 311-320.

(29) Cao, F.; Miller, W. L. A new algorithm to retrieve chromophoric dissolved organic matter (CDOM) absorption spectra in the UV from ocean color. J. Geophys. Res. C 2015, 120 (C1), 496-516. 